\title{
Herbal medicine and nervous system diseases in the Rif of Morocco
}

\author{
Noureddine Chaachouay, Lahcen Zidane \\ Nutrition, health and environment Laboratory, Department of Biology, Faculty of Sciences, Ibn Tofail University, B.P. 133, 14000, Kenitra, Morocco. \\ *Corresponding Author: Tel: $+212677488621 \quad$ Email: nour.chay@gmail.com \\ ORCID iD: https://orcid.org/0000-0002-0745-6268
}

\section{Abstract}

Objective: The aim of this study was to assess the knowledge and use of medicinal plants in the treatment of neurological diseases in the Rif region of northern Morocco. Methods: An ethnobotanical survey was carried out in the Rif (northern Morocco) from 2016 to 2018. In order to gather information about indigenous medicinal plants and local ethnomedical knowledge, 625 local traditional herbalists and users of these plants were interviewed. The data were collected through semi-structured interviews and group discussions, analyzed, and compared by quantitative ethnobotanical indices such as family importance value, relative frequency of citation, plant part value (PPV), fidelity level, and informant consensus factor (ICF). Results: Data were collected from 31 medicinal plant species belonging to 14 botanical families. Asteraceae and Lamiaceae were the most commonly reported medicinal plants, with 5 species each. Concerning the diseases treated, epilepsy problems have the highest ICF (0.99). The survey revealed that leaves were the most used part of the plants (PPV $=34.7 \%$ ), and the most commonly used preparation was an infusion (41.6\%). Conclusions: There exists indigenous ethnomedical knowledge of medicinal plants in the Moroccan Rif to treat neurologic diseases. Based on our findings, we recommend that phytochemical and pharmacologic research be considered to discover potential treatments from these documented plants.

\section{Introduction}

Humans have always used medicinal plants (MPs) to treat themselves and fight diseases. In all ancient civilizations and on all continents, one finds traces of this use. Thus, even today, despite the progress of pharmacology, the therapeutic use of plants is very present in some countries, especially developing ones. Neurologic diseases are strongly associated with the activation of inflammatory pathways, and long-term use of anti-inflammatory drugs reduces the risk of developing these diseases. In Sao Tome and Príncipe,, several medicinal plants are used both for their positive effects in the nervous system (treatment of mental disorders, analgesics) and for their anti-inflammatory properties. Morocco, by its biogeographical position, offers a very rich ecological and floristic diversity constituting a true plant genetic reserve, with about 4500 species belonging to 940 genera and 135 families; the mountainous regions of the Rif and Atlas being the most important areas for endemism. Indeed, phytotherapy has always occupied an important place in the traditions of medication in Morocco, and the Rif region is a concrete example. Analysis of the Moroccan medicinal bibliography shows that the data on regional medicinal plants are very fragmentary and dispersed. Accordingly, we chose to conduct this ethnobotanical study in the Moroccan Rif, which has considerable lithological, structural, biological, and floristic diversity because of its relief, topography, and geographic location. The aim of this study was to assess the knowledge and use of medicinal plants in the treatment of neurologic diseases in the region of northern Morocco.

\section{Materials and Methods}

Study Area: The research was taken out in the Rif (Northern Morocco) where the Tangier-Tetouan-Al Hoceima region was latitude in the North and $4^{\circ}$ to $6^{\circ}$ of longitude in the East. It is bordered in the North by the Strait of Gibraltar and the Mediterranean Sea, in the South by the Rabat-Sale-Kenitra region and Fez-Meknes region, in the East by the Atlantic Ocean. Methodology: In order to gather information on MPs used for treating neurologic disorders, an ethnobotanical survey was conducted from June 30,2016 , to June 1,2018 . Interviews were administered as semistructured, and openended interviews were conducted through face-to-face interviews and focus groups. The inclusion criterion was that individuals be qualified health care professionals, such as pharmacists, herbalists, practitioners, and therapists; the exclusion criterion was not living in the study area. In total, 625 informants aged 17 to 80 years were randomly selected for interviews in the study area (at hospitals, pharmacies, houses, mosques, and weekly markets). The questionnaire used consists of 2 parts: the first part deals with the demographic characteristics of the informants, and the second focuses on the plants used in the treatment of the nervous system diseases. Data Analysis: The results of the ethnobotanical survey were analyzed using the family importance value (FIV), relative frequency of citation (RFC), plant part value (PPV), fidelity level (FL), and informant consensus factor (ICF). All statistical analyses were carried out with Statistical Package forSocial Science (SPSS), version 21, and Microsoft Excel 2010. located. It extends between $34^{\circ}$ to $36^{\circ}$ of Eastern Region, and in the West by the

\section{Results}

In total, 625 local informants were interviewed

including 321 women and 304 men (with a female to male ratio of 1.06). In the Moroccan Rif, herbs work for the treatment of conditions for both women and men; in our study, women made up $51.3 \%$ of participants and men $48.7 \%$. A total of 31 medicinal plant species belonging to 14

botanical families were used to treat neurologic diseases in

the study area. The most representative families, in terms of number of species, were Asteraceae and Lamiaceae (5 species each), and Cucurbitaceae and Solanaceae (4 species each); other families were represented by 1 or 2 species only. To evaluate the relative importance of reported MPs, RFC was calculated based on the informants' citations for the specific plant under study. Values ranged from 0.002 to 0.214 . Marrubium echinatum L. exhibited the highest RFC (0.214), followed by Allium cepa L. (0.197), Aloysia citrodora L. (0.168), Myristica fragrans L. (0.154), and Artemisia herba-alba L (0.152). The lowest RFC (0.002) was exhibited by eight MPs. In the Rif area, infusion remains the most dominant method of preparation $(41.6 \%)$, followed by cataplasm (30.36\%) and decoction (27.6\%). The incidences of the other modes of preparation (fumigation and maceration) combined does not exceed $0.44 \%$.

\section{Conclusions}

In total, 625 local informants were interviewed including 321 women and 304 men (with a female to male ratio of 1.06). In the Moroccan Rif, herbs work for the treatment of conditions for both women and men; in our study, women made up 51.3\% of participants and men $48.7 \%$. A total of 31 medicinal plant species belonging to 14 botanical families were used to treat neurologic diseases in The Moroccan Rif region has a great reservoir of ethnomedical knowledge, particularly regarding the use of medicinal plants in primary health care. Locals of the region have tremendous traditional knowledge to utilize plants for the treatment of neurologic diseases. On the basis of our results, we recommend that plants with high ICF and FL values receive further phytochemical and pharmacologic investigation. We also recommend that protection measures be adopted for the conservation of these potential medicinal plant species.

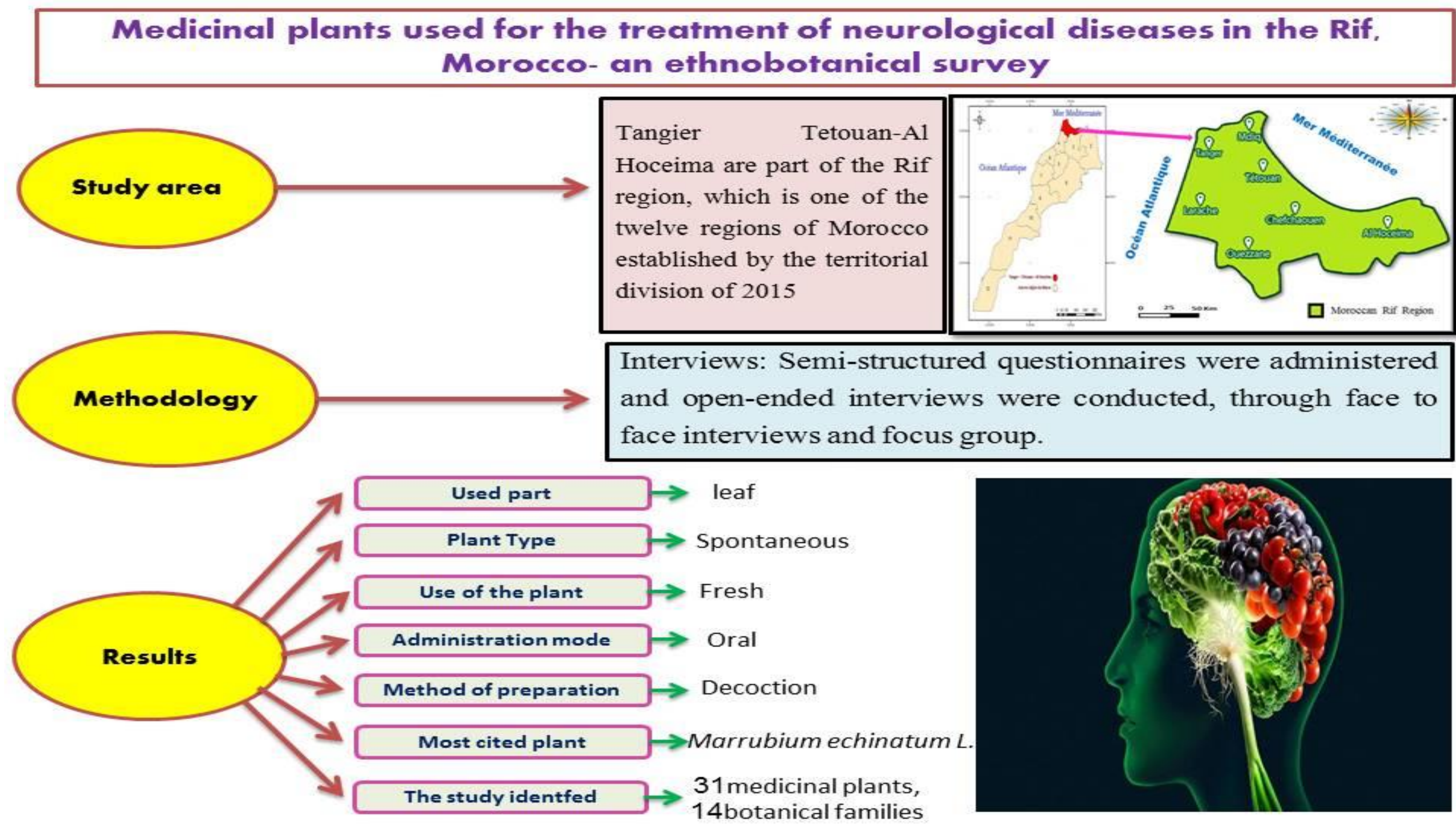

